\title{
Establishment of a Mouse Thrombocytopenia Model Induced by Cyclophosphamide
}

\author{
NIE Hong ${ }^{1,2, *}$, LI Kong-yan ${ }^{1,2}$, ZHANG Xiao-qi ${ }^{2,3}$, FENG Xue-ying ${ }^{4}$, YANG Duan-rong ${ }^{4}$, WU \\ Yu-si ${ }^{1}$, ZHOU Jiu-yao ${ }^{5}$, YE Wen-cai ${ }^{2,3,{ }^{*}}$
}

(1. College of Pharmacy, Jinan University, Guangzhou 510632, P.R. China; 2. Guangdong Province Key Laboratory of Pharmacodynamic

Constituents of TCM and New Drugs Research, Jinan University, Guangzhou 510632, P.R. China; 3. Institute of Traditional Chinese Medicine and

Natural Products, College of Pharmacy,Jinan University, Guangzhou 510632, P.R. China; 4. International School, Jinan University, Guangzhou

510632, P.R. China;5. Guangzhou University of Chinese Medicine, Guangzhou 510006, P.R. China)

\begin{abstract}
An experiment was conducted to compare the effects of two mouse thrombocytopenia models induced by cyclophosphamide at two different administration routes to determine a proper cyclophosphamide administration route that could cause stable thrombocytopenia. A suitable drug dosage that could induce thrombocytopenia in mouse efficiently with the definite administration route was then investigated. BALB/c mice were randomly divided into Normal, Model A and Model B groups. To Model A, $200 \mathrm{mg} / \mathrm{kg}$ of cyclophosphamide was given by vena caudalis injection as first dose and $30 \mathrm{mg} / \mathrm{kg}$ as maintenance dose by intraperitoneal injection at the following 6 days. To Model B, $150 \mathrm{mg} / \mathrm{kg}$ of cyclophosphamide was given by subcutaneous injection once a day for consecutive 3 days. All groups were under investigation for 15 days. The result suggested that a decrease in the number of blood platelets of Model B at the 7th day were significantly than that of Normal. Other platelet related indices like platelet distribution width, mean platelet volume and platelet-large cell ratio of Model B increased significantly in comparison with those of Normal group. The platelets count was reduced but fluctuated greatly, and more than half of the mice died in Model A. Therefore, subcutaneous injection of cyclophosphamide for 3 days was used for the cyclophosphamide dosage test. BALB/c mice were randomly divided into Normal, cyclophosphamide low dose $(100 \mathrm{mg} / \mathrm{kg})$, medium dose $(120 \mathrm{mg} / \mathrm{kg})$ and high dose $(140 \mathrm{mg} / \mathrm{kg})$ groups. All groups were under investigation for 11 days. Though all 3 dosages successfully initiated thrombocytopenia as the platelets number dropped at the 7th day, the low dose was considered to be a suitable one that was of high efficacy and low toxicity. Thus, BALB/c mice challenged by subcutaneous injection of cyclophosphamide $100 \mathrm{mg} / \mathrm{kg}$ per day for 3 consecutive day is one simple, feasible and stable mouse thrombocytopenia model that could be used for pharmacodynamic test of the drugs which are supposed to have platelets increasing effect.
\end{abstract}

Key words: Thrombocytopenia; Cyclophosphamide; Model

\section{环磷酰胺诱导小鼠血小板减少症模型的建立}

\author{
聂 红 ${ }^{1,2, *}$, 李孔燕 ${ }^{1,2}$, 张晓琦 ${ }^{2,3}$, 冯雪莹 ${ }^{4}$, 杨端容 ${ }^{4}$, 吴玉斯 ${ }^{1}$, 周玖瑶 ${ }^{5}$, 叶文才 $^{2,3,{ }^{*}}$
}

(1. 暨南大学 药学院, 广州 510632; 2. 暨南大学 中药药效物质基础及创新药物研究广东省高校重点实验室, 广州 510632; 3. 暨南大学 药

学院中药及天然药物研究所, 广州 510632; 4. 暨南大学 国际学院, 广州 510632; 5. 广州中医药大学, 广州 510006)

摘要: 比较由环磷酰胺两种不同给药方式诱导小鼠血小板减少症模型的效果, 并对效果较稳定的一种给药方 式进行最佳造模剂量摸索, 以期确定一个造模效果较好, 毒副作用较低, 利于观察治疗药物疗效的血小板减少症 模型。模型 A 组, 第 1 天尾静脉注射环磷酰胺 $200 \mathrm{mg} / \mathrm{kg}$, 然后连续 $6 \mathrm{~d}$, 每天 1 次以维持剂量 $30 \mathrm{mg} / \mathrm{kg}$ 腹腔注 射环磷酰胺。模型 $\mathrm{B}$ 组, 按 $150 \mathrm{mg} / \mathrm{kg}$ 皮下注射环磷酰胺, 每天 1 次, 连续 $3 \mathrm{~d}$ 。结果显示模型 $\mathrm{B}$ 组造模效果较 好, 故以模型 B 组给药方法进行剂量摸索实验。由第 7 天的血小板计数可知环磷酰胺低 $(100 \mathrm{mg} / \mathrm{kg}) 、$ ( 120 $\mathrm{mg} / \mathrm{kg}$ )、高 (140 mg/kg) 剂量均可引起血小板减少症, 而低剂量组与其他组比较有高效低毒的特点, 更有利于观

Received date: 2009-04-31; Accepted date: 2009-08-18

Foundation items: Supported by the 211 Project of Jinan University; the Team Project of Natural Science Foundation of Guangdong Province (8351063201000003); the Popular Science Foundation of Science \& Technology Bureau of Guangzhou City (2008KP055); the Natural Science Foundation of Guangdong Province (06025198); the Jinan University Natural Science Foundation (51204017); the Science and Technology Innovation Project for Undergraduates (cx08120)

${ }^{*}$ Corresponding author (通讯作者), E-mail: tnieh@jnu.edu.cn; chywc@yahoo.com.cn

收稿日期：2009-04-31；接受日期：2009-08-18 
察治疗药物的作用, 可用于具有升血小板作用药物的药效学研究。

关键词: 血小板减少症; 环磷酰胺; 模型

中图分类号：Q955; R558; R979.11 文献标识码：A 文章编号：0254-5853-(2009)06-0645-08

Cyclophosphamide is a synthetic alkylating agent chemically related to the nitrogen mustards with antineoplastic and immunosuppressive activities, and was introduced as an antitumour agent in 1958. The important factor for therapeutic and toxic effects of cyclophosphamide is the requirement of metabolic activation by hepatic microsomal cytochrome $\mathrm{P}_{450}$ mixed functional oxidase system. In the liver, cyclophosphamide is converted to the active metabolites aldophosphamide and phosphoramide mustard, which bind to DNA, thereby inhibiting DNA replication and initiating cell death. The renal cleavage of inactive circulating metabolites will bring about toxic byproducts like acrolein, which is the causative agent in cyclophosphamide cystitis (Cox et al, 1979).

Cyclophosphamide, as a cell cycle-independent DNA and protein alkylating agent, which has a wide spectrum of anti-tumor activity, is one of the common chemical drugs for the therapy of malignant lymphomas, leukaemias, neuroblastoma, retinoblastoma and carcinomas of the ovary, breast, endometrium and lung, usually in combination with other chemotherapeutic drugs (de Jonge et al, 2005). Fulminant cardiac toxicity is the most severe dose-limited toxicity of cyclophosphamide whose other side effects are hematopoietic depression, hemorrhagic cystitis, gonadal dysfunction, alopecia, nausea, gastrointestinal toxicity, renal toxicity, antidiuretic effect and vomiting. Also, it was reported that cyclophosphamide could induce chromosome aberration of bone marrow and liver cells (He et al, 1984). In conventional chemotherapy, cyclophosphamide is one of the most commonly employed drugs which are applied in high dose regimen to treat metastatic breast cancer (Legha et al, 1979). In the setting of this, host toxicity will lead to the limitation of the therapeutic efficacy of this drug and the systemic distribution of activated drug metabolites that have significant cytotoxic effects including cardiac and renal toxicity (Chen et al, 1996).

We chose two candidate models reported as thrombocytopenia model induced by cyclophosphamide to verify their feasibility. In New Drug Pharmacological Research Methods (Lü, 2007), it notes that cyclophosphamide induced leucopenia animal model can also be the model of thrombocytopenia. A few original articles illustrated platelets count reduced significantly in the cause of leucopenia of mice (Shou et al, 2008). Therefore, we focus on two mice models of thrombopenia induced by cyclophosphamide at two different administration routes to verify a definite one. Then the assured administration method was used in the following experiment to find out a suitable cyclophosphamide dose.

\section{Materials and Method}

\subsection{Animals and materials}

1.1.1 Animals Special pathogen free BALB/c mice, weighed $(19 \pm 2) \mathrm{g}$, half male and half female, were purchased from medical science experimental animal center of Guangdong Province in China (Certificate NO.SCXK (Guangdong) 2003-0002). The mice were kept in the cages at $24^{\circ} \mathrm{C}, 65 \%$ humidity, with alternating $12 \mathrm{~h}$ light/12 h dark (Certificate NO.2008-0085). Animals were given free access to standard laboratory mice chow and tap water. Animal welfare and experimental procedures were strictly in accordance with the guide for the care and use of laboratory animals and the related ethical regulations of Jinan University and Guangzhou University of Chinese Medicine according to the internationally accepted principles.

1.1.2 Materials Cyclophosphamide was purchased from HengRui Pharmaceutical limited company, Jiangsu (Batch number: 07112221). Calcium chloride $(500 \mathrm{~g}$, Guangzhou Chemical Agent Factory, 20070801-1), acetic acid $(500 \mathrm{~mL}$, Tianjing No.1 Chemical Agent Factory, 060707) and perchloric acid $(500 \mathrm{~mL})$ were analytically pure.

Sysmex KX-21 hematology analyzer (TOA Medical Electronics, Inc, Kobe, Japan) and cell packs diluents (TOA Medical Electronics, Inc, Kobe, Japan) was provided by Huarui Hospital affiliated to Southern Medical University. TU-1810S UV-VIS spectrophotometer (Beijing Puxi General Equipment Co.Ltd.), Anke TDL80-2B table centrifuge (Shanghai Anting Scientific Instrument Plant), DK-8D electrothermal thermostatic water tank (Shanghai Yiheng Technical Co. Ltd.), blood cell counting chamber (Shanghai Qiujing Biochemical Reagent and Equipment Co.Ltd.), Nikon ECLIPSE TS100 fluorescence inverted microscope (Nikon Co. Ltd.), were provided by 
Pharmacy College of Jinan University.

\subsection{Experimental protocol}

\subsubsection{Comparison of two thrombopenia models}

1.2.1.1 Animal model Twenty-six BALB/c mice, half male and half female, were divided into three groups randomly due to their weight and gender, namely Normal, Model A and Model B with 8, 10 and 8 mice, respectively. The Model A had two extra mice to account for its high death rate in the preliminary experiment. Model A received $200 \mathrm{mg} / \mathrm{kg}$ of cyclophosphamide by vena caudalis injection as first dose and $30 \mathrm{mg} / \mathrm{kg}$ as maintenance dose by intraperitoneal injection in the following 6 days (Zhang et al, 2003). Model B received $150 \mathrm{mg} / \mathrm{kg}$ of cyclophosphamide by subcutaneous injection for 3 days (He et al, 2003). The capacity of dosage of the drug is $0.1 \mathrm{~mL} / 10 \mathrm{~g}$.

\subsubsection{Observation indexes}

1.2.1.2.1 General condition The usual activities, fur luster, amount of diet and drinking, conditions of urination and defecation, and the change of weight and mortality of the mice were observed closely. The animals were weighed everyday. This process lasted for 15 days. 1.2.1.2.2 Blood cell analyses A $10 \mu \mathrm{L}$ blood sample was collected by tail cut before administration at the $1 \mathrm{st}$, 4th, 7th, 11th, and 15th day mornings and transferred into a $1.5 \mathrm{~mL}$ EP tube containing $0.5 \mathrm{~mL}$ cell pack diluents. Blood cell analyses were conducted soon after the collection. The day interval was selected based on previous reports (Zhang et al, 2003. He et al, 2003) and changed slightly according to preliminary experiment.

1.2.1.2.3 Measurement of clotting time On the 16th day, a glass capillary (Inner diameter $=0.9 \sim 1.1 \mathrm{~mm}$, length $=10 \mathrm{~cm}$ ) was inserted into one eye of mice. The capillary was removed and placed on the desk horizontally when the blood full filled it. Every 30 s the capillary was broke and stretched gently to see if there was fibrin threads of blood at the breakage point. The time from bleeding to the fibrin threads occurred was recorded. These were performed at a room temperature of $16^{\circ} \mathrm{C}$.

1.2.1.2.4 Bone marrow nucleated cells count Mice were sacrificed by cervical spine dislocation, then dissected to remove the right femur. The clingy muscle of femur was eliminated and the ends were then snipped off. The medullary cavity was washed by $10 \mathrm{~mL} 3 \%$ glacial acetic acid in $10 \mathrm{~mL}$ syringe and the collected wash was scattered through type 4 syringe needles. Bone marrow nucleated cells were counted by dropping one drop of washing liquid on the globulimeter and observed under microscope $(10 \times 40)$. Cells were calculated as the total amount of cells from four large grid multiples $2.5 \times 10^{4} /$ femur

\subsubsection{Modification of thrombopenia model}

1.2.2.1 Animal model $48 \mathrm{BALB} / \mathrm{c}$ mice, half male and half female, were randomly divided into Normal, Cyclophosphamide low, medium and high dose groups with each of 12 mice due to their weight and gender. The three dosage groups were given 100, 120, $140 \mathrm{mg} / \mathrm{kg}$ cyclophosphamide by subcutaneous injection respectively. The volume of dosage is $0.1 \mathrm{~mL} / 10 \mathrm{~g}$. Mice in Normal group received the same volume of normal saline.

\subsubsection{Observation indexes}

1.2.2.2.1 General condition The same as described in 1.2.1.2.1. This process lasted for 11 days.

1.2.2.2.2 Blood cell analyses A $10 \mu \mathrm{L}$ blood sample was collected by tail cut before administration at the $1 \mathrm{st}$, 7 th and 11th day mornings and transferred into a $1.5 \mathrm{~mL}$ EP tube with $0.5 \mathrm{~mL}$ cell pack diluents in it. Blood cell analyses were analyzed soon after the collection.

1.2.2.2.3 Measurement of clotting time Clotting time measurement was performed at room temperature $16^{\circ} \mathrm{C} 6$ hours after taking blood for blood cells test on the 11 th day. Two methods were used for the assay.

Capillary tube method: The same as described in 1.2.1.2.3

Slide method: After the removal of one eye of each mouse, two drops of blood was dropped onto the slide, one drop for one slide end. One of the blood drops was teased every $30 \mathrm{~s}$ with a needle until fibrin threads of blood appeared. The time from bleeding to the appearance of fibrin threads was recorded. The other drop of blood was used for recheck.

1.2.2.2.4 Bone marrow nucleated cells count The left femur of mice was harvested for bone marrow nucleated cells count. For detailed procedure see 1.2.1.2.4.

1.2.2.2.5 Bone marrow DNA contents Mice were sacrificed by cervical spine dislocation, then dissected to remove the right femur, eliminate the clingy muscle and then snip off the ends. The right femur bone marrow was harvested by washing the cavity with $10 \mathrm{~mL} 5 \mathrm{mmol} / \mathrm{L}$ $\mathrm{CaCl}_{2}$ in a $10 \mathrm{~mL}$ syringe with type 6 syringe needle. The washings were then placed into $4{ }^{\circ} \mathrm{C}$ refrigerator for 30 min, centrifuged at $2500 \mathrm{r} / \mathrm{min}$ for $15 \mathrm{~min}$, and the supernatant was discarded. $5 \mathrm{~mL} 0.2 \mathrm{~mol} / \mathrm{L}$ of $\mathrm{HClO}_{4}$ was then added into the precipitant, mixed thoroughly, and heated at $90^{\circ} \mathrm{C}$ by thermostatic water bath for $15 \mathrm{~min}$. After cooling down, it was centrifuged at $3500 \mathrm{r} / \mathrm{min}$ for 
10 min. The absorption value of the supernatant was measured under UV-VI spectrophotometer at $268 \mathrm{~nm}$.

\subsection{Statistical analysis}

Data are presented as $(\bar{X} \pm S)$. Statistical analysis was performed with the independent-samples $t$ test by SPSS 13.0 software. Differences were considered significant when $P<0.05$.

\section{Results}

\subsection{Comparison of two thrombopenia models}

2.1.1 General condition At the 1st day, the hair of the mice in the two model groups became erect as soon as the cyclophosphamide was injected. Moreover, the hair color was not as bright as the ones of the Normal group. They also developed bowed backs and dysphoria. Mice of Model A group were much worse compared with those of Model B group. All these appearances disappeared one day after the last administration. Mice in Model A died from the 6th day, the death rate was $40 \%$ on the 7 th day and came to final $60 \%$ on the 15 th day. As to Model B, there was no death within 13 days (Fig.1) Autopsy of dead mice in both model groups showed hepatomegaly and the livers were grainy, even some hearts were covered with white particles.

The body weights of female mice in Model B group first decreased after injecting cyclophosphamide. However, on the 10th day they began to rise to almost the Normal level by the 15 th day where the males continued to decrease. The weight of the Normal group mice increased gradually and tended to be stable at later periods. However, the weight of the Model groups dropped rapidly after injection of cyclophosphamide but began to rise 3 days after ceasing injections to the original level on the 15th day (Fig2).

2.1.2 Blood cell analyses In comparison to the Normal group, Model A platelets count decreased on day 7 and day 15 to about $59 \%$ and $74 \%$ of the Normal level respectively (Fig.3); platelet distribution width (Fig.4), mean platelet volume (Tab.1) and platelet-large cell ratio (Tab.2) did not change; white blood cells count dropped sharply on day 4 and day 7 (Fig.5). When Model B was compared with the Normal group, its platelets count decreased on day 7 and day 11 to about $33 \%$ and $75 \%$ of the Normal level, respectively (Fig.3); platelet distribution width increased on day 7 and day 11 (Fig.4); mean platelet volume increased on day 4 , day 7 and day 11 (Tab. 1); platelet-large cell ratio increased on day 4

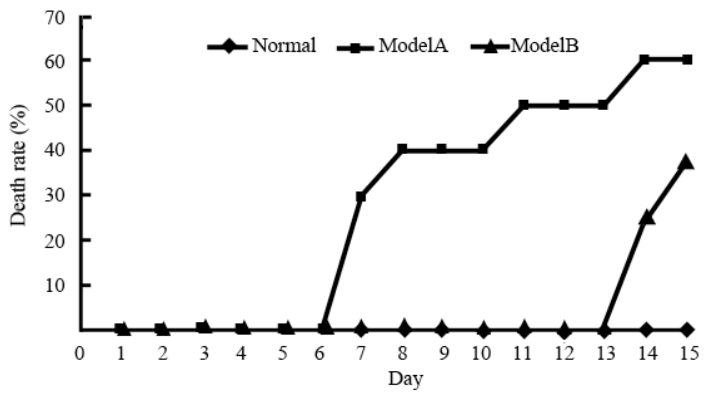

Fig. 1 Death rate of BALB/c mice affected by cyclophosphamide

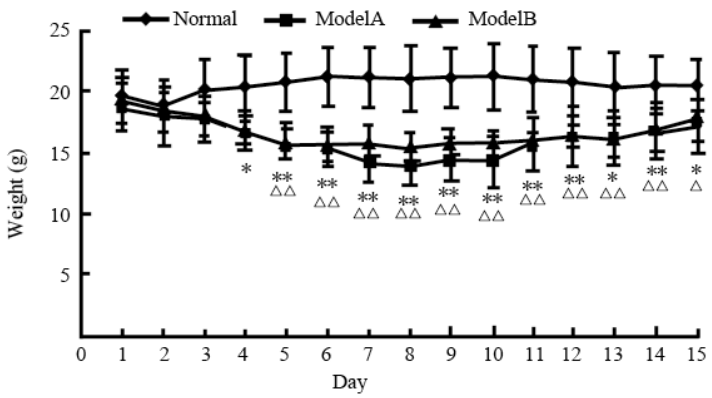

Fig. 2 Weight changes of BALB/c mice affected by cyclophosphamide

Data were expressed as $(\bar{X} \pm s)$. Model A vs Normal: $* P<0.05$, ${ }^{* *} P<0.01$; Model B vs Normal: ${ }^{\triangle} \boldsymbol{P}<0.05,{ }^{\triangle \triangle} \boldsymbol{P}<0.01$.

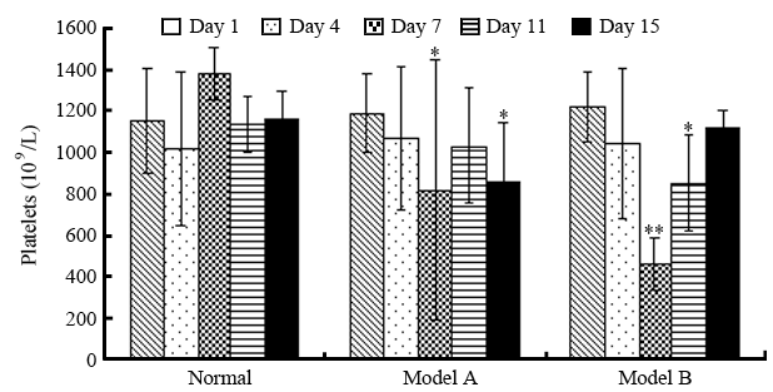

Fig. 3 Platelets of mice at different phases induced by cyclophosphamide

Data were expressed as $(\bar{X} \pm s)$. Compared to Normal on the same day: $* P<0.05, * * P<0.01$.

Tab. 1 Mean platelet volume of mice at different phases induced by cyclophosphamide $(\bar{X} \pm s)$

\begin{tabular}{|c|c|c|c|c|c|c|c|c|c|c|c|}
\hline \multirow{2}{*}{ Group } & \multirow{2}{*}{ Dose (mg/kg) } & \multicolumn{10}{|c|}{ Mean platelet volume (fl) } \\
\hline & & $\mathrm{N}$ & Day 1 & $\mathrm{~N}$ & Day 4 & $\mathrm{~N}$ & Day 7 & $\mathrm{~N}$ & Day 11 & $\mathrm{~N}$ & Day 15 \\
\hline Normal & - & 8 & $5.92 \pm 0.19$ & 8 & $5.92 \pm 0.13$ & 8 & $5.93 \pm 0.20$ & 8 & $5.77 \pm 0.13$ & 8 & $6.10 \pm 0.26$ \\
\hline Model A & $30(1$ st dose:200) & 10 & $5.87 \pm 0.10$ & 10 & $5.96 \pm 0.11$ & 6 & $6.06 \pm 0.36$ & 5 & $5.74 \pm 0.21$ & 4 & $6.11 \pm 0.25$ \\
\hline Model B & 150 & 8 & $5.86 \pm 0.15$ & 8 & $6.18 \pm 0.13^{* *}$ & 8 & $6.24 \pm 0.25^{*}$ & 8 & $6.23 \pm 0.16^{* *}$ & 5 & $6.01 \pm 0.36$ \\
\hline
\end{tabular}

Compared to Normal on the same day, ${ }^{*} \mathrm{P}<0.05,{ }^{* *} \mathrm{P}<0.01$. 
Tab. 2 Platelet-large cell ratio of mice at different phases induced by cyclophosphamide $(\bar{X} \pm s)$

\begin{tabular}{|c|c|c|c|c|c|c|c|c|c|c|c|}
\hline \multirow{2}{*}{ Group } & \multirow{2}{*}{ Dose (mg/kg) } & \multicolumn{10}{|c|}{ Platelet-large cell ratio (\%) } \\
\hline & & $\mathrm{N}$ & Day 1 & $\mathrm{~N}$ & Day 4 & $\mathrm{~N}$ & Day 7 & $\mathrm{~N}$ & Day 11 & $\mathrm{~N}$ & Day 15 \\
\hline Normal & - & 8 & $2.63 \pm 1.89$ & 8 & $2.75 \pm 1.04$ & 8 & $2.88 \pm 1.25$ & 8 & $2.50 \pm 0.76$ & 8 & $3.75 \pm 1.28$ \\
\hline Model A & $30(1$ st dose: 200$)$ & 10 & $2.00 \pm 0.94$ & 10 & $2.90 \pm 0.88$ & 6 & $3.33 \pm 1.37$ & 5 & $2.60 \pm 0.55$ & 4 & $4.25 \pm 0.50$ \\
\hline Model B & 150 & 8 & $2.50 \pm 1.31$ & 8 & $4.38 \pm 1.77^{*}$ & 8 & $4.00 \pm 1.77$ & 8 & $4.00 \pm 0.76^{* *}$ & 5 & $3.60 \pm 1.14$ \\
\hline
\end{tabular}

Compared to Normal on the same day, ${ }^{*} P<0.05,{ }^{* *} P<0.01$.

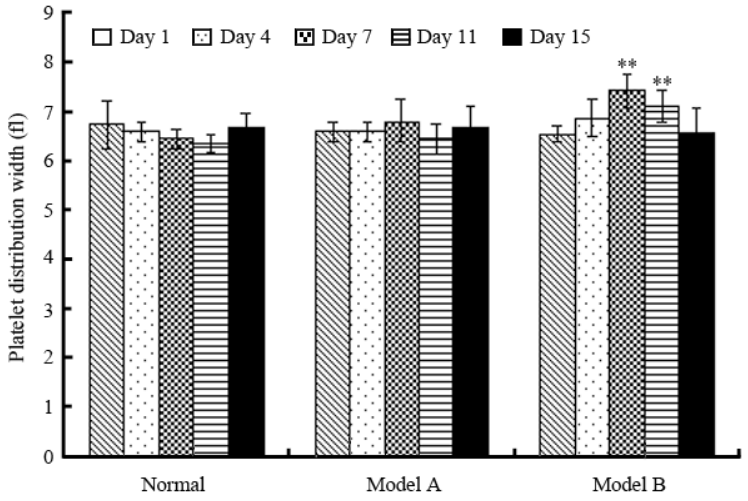

Fig. 4 Platelet distribution width of mice at different phases induced by cyclophosphamide

Data were expressed as $(\bar{X} \pm s)$. Compared to Normal on the same day: $* * P<0.01$

and day 11 (Tab.2); white blood cells count dropped sharply on day 4 and day 7 as Model A did (Fig.5). All differences between Normal group and model groups were of significance unless otherwise mentioned.

2.1.3 Clotting time and bone marrow nucleated cells count The rest of mice in two model groups were less than 6. There was no significant difference of clotting time and bone marrow nucleated cell count between Normal and model groups (data not shown).

\subsection{Modification of thrombopenia model}

2.2.1 General condition The hair of the mice in the 3 models became erect as soon as cyclophosphamide was

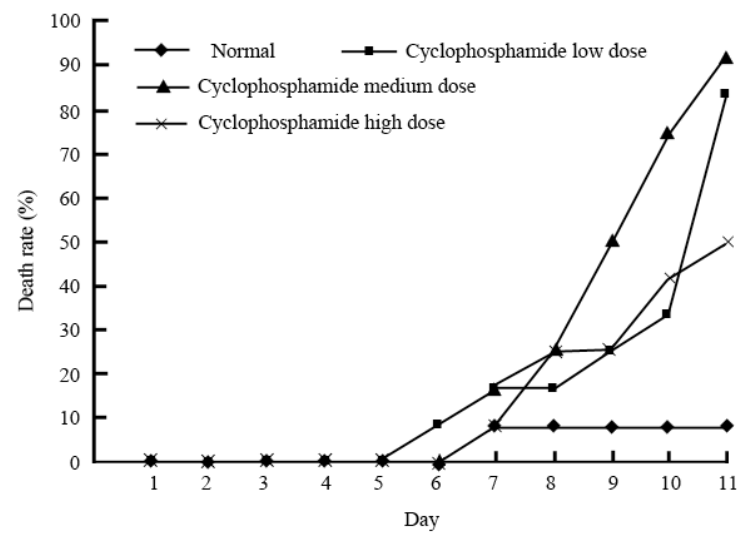

Fig. 6 Death rate of BALB/c mice affected by cyclophosphamide

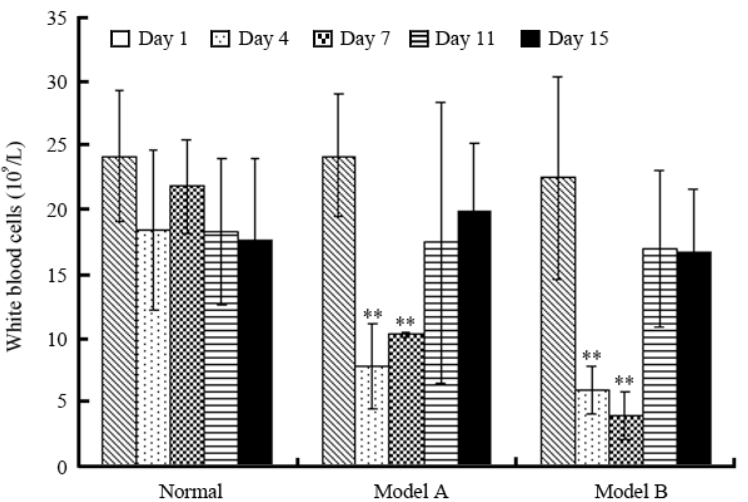

Fig. 5 White blood cells of mice at different phases induced by cyclophosphamide

Data were expressed as $(\bar{X} \pm s)$. Compared to Normal on the same day: ${ }^{*} P<0.01$.

injected, and the hair color lacked the brightness of the Normal group. All these appearances disappeared one day after the last dosage. Mice in model groups began to die from the 6th day (Fig.6). One mouse in Normal group died on the 7 th day without abnormal pathology. Autopsy of the dead mice of model groups showed hepatomegaly, with the livers grainy, some hearts were covered with white particles, and some even contracted pneumonia or renal atrophy.

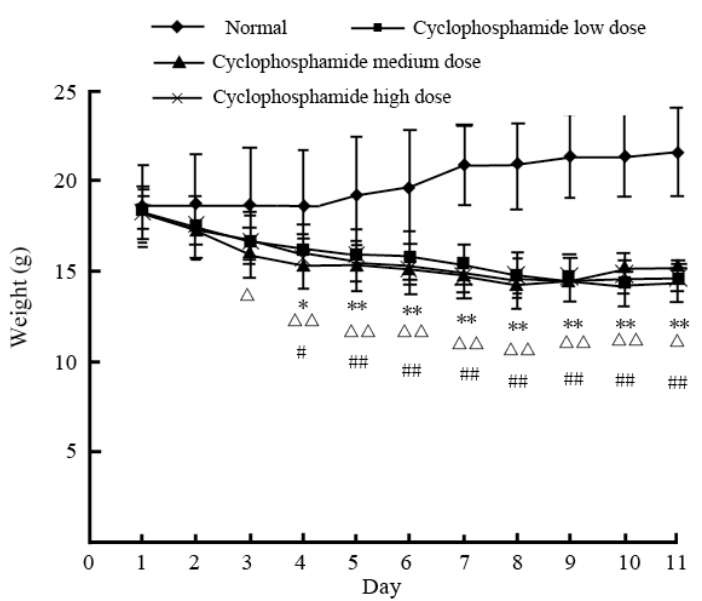

Fig. 7 Effect of cyclophosphamide on weight of $\mathrm{BALB} / \mathrm{c}$ mice

Data were expressed as $(\bar{X} \pm s)$. Cyclophosphamide low dose vs Normal: $* P<0.05, * * P<0.01$; Cyclophosphamide medium dose vs Normal: ${ }^{\triangle} P<0.05,{ }^{\triangle} P<0.01$; Cyclophosphamide high dose vs Normal: ${ }^{\#} P<0.05,{ }^{\#} P<0.01$. 
Tab. 3 Platelet distribution width of BALB/c mice influenced by cyclophosphamide on day 1 , day 7 and day $11(\bar{x} \pm s)$

\begin{tabular}{lccccccc}
\hline \multirow{2}{*}{ Group } & \multirow{2}{*}{ Dose $(\mathrm{mg} / \mathrm{kg})$} & \multicolumn{5}{c}{ Platelet distribution width (fl) } \\
\cline { 3 - 8 } & & $\mathrm{N}$ & Day 1 & $\mathrm{N}$ & Day 7 & $\mathrm{N}$ & Day 11 \\
\hline Normal & - & 12 & $7.58 \pm 0.88$ & 11 & $6.55 \pm 0.46$ & 11 & $6.49 \pm 0.21$ \\
Cyclophosphamide low dose & 100 & 12 & $7.06 \pm 0.89$ & 10 & $6.63 \pm 3.51$ & 2 & $8.22 \pm 0.14^{* *}$ \\
Cyclophosphamide medium dose & 120 & 12 & $6.50 \pm 2.07$ & 10 & $5.79 \pm 4.12$ & 0 & - \\
Cyclophosphamide high dose & 140 & 12 & $5.81 \pm 2.74$ & 11 & $4.99 \pm 3.99$ & 6 & $9.91 \pm 2.08^{*}$ \\
\hline
\end{tabular}

Compared to Normal on the same day, ${ }^{*} P<0.05,{ }^{* *} P<0.01$.

Tab. 4 Mean platelet volume of BALB/c mice influenced by cyclophosphamide on day 1 , day 7 and day $11(\bar{X} \pm s)$

\begin{tabular}{lccccccc}
\hline \multirow{2}{*}{ Group } & \multirow{2}{*}{ Dose $(\mathrm{mg} / \mathrm{kg})$} & \multicolumn{5}{c}{ Mean platelet volume (fl) } \\
\cline { 3 - 8 } & & $\mathrm{N}$ & Day 1 & $\mathrm{N}$ & Day 7 & $\mathrm{~N}$ & Day 11 \\
\hline Normal & - & 12 & $6.33 \pm 0.28$ & 11 & $5.96 \pm 0.21$ & 11 & $5.97 \pm 0.13$ \\
Cyclophosphamide low dose & 100 & 12 & $6.15 \pm 0.36$ & 10 & $6.27 \pm 2.51$ & 2 & $6.92 \pm 0.14^{* *}$ \\
Cyclophosphamide medium dose & 120 & 12 & $5.74 \pm 1.82$ & 10 & $4.57 \pm 3.16$ & 0 & - \\
Cyclophosphamide high dose & 140 & 12 & $5.14 \pm 2.41$ & 11 & $4.11 \pm 3.27$ & 6 & $7.39 \pm 0.63^{* *}$ \\
\hline
\end{tabular}

Compared to Normal on the same day, ${ }^{* *} P<0.01$.

Tab. 5 Platelet-large cell ratio of BALB/c mice influenced by cyclophosphamide on day 1 , day 7 and day $11(\bar{X} \pm s)$

\begin{tabular}{lccccccc}
\hline \multirow{2}{*}{ Group } & \multirow{2}{*}{ Dose $(\mathrm{mg} / \mathrm{kg})$} & $\mathrm{N}$ & Day 1 & $\mathrm{N}$ & Day 7 & $\mathrm{~N}$ & Day 11 \\
\cline { 3 - 8 } & - & 12 & $0.04 \pm 0.02$ & 11 & $0.03 \pm 0.01$ & 11 & $0.03 \pm 0.01$ \\
Normal & 100 & 12 & $0.04 \pm 0.02$ & 10 & $0.04 \pm 0.03$ & 2 & $0.06 \pm 0.00^{* *}$ \\
Cyclophosphamide low dose & 120 & 12 & $0.04 \pm 0.01$ & 10 & $0.03 \pm 0.03$ & 0 & - \\
Cyclophosphamide medium dose & 140 & 12 & $0.03 \pm 0.02$ & 11 & $0.03 \pm 0.04$ & 6 & $0.10 \pm 0.07$ \\
Cyclophosphamide high dose & & &
\end{tabular}

Compared to Normal on the same day, ${ }^{* *} P<0.01$.

The weight of the Normal group mice increased gradually and tended to be stable at the end stage while the Model ones dropped rapidly after administrating cyclophosphamide, especially in the medium dose group (Fig7).

2.2.2 Blood cell analyses In comparison to the Normal group, the following blood cell analytic results had significant differences. Platelet decreased on day 7 of 3 dosage groups and on day 11 of high dose group (Fig.8). The platelets count of mice in cyclophosphamide low dose group on day 7 was $30 \%$ of the Normal ones while the medium and high dose groups were $18 \%$ and $21 \%$, respectively. Platelet distribution width increased on day 11 of low and high dose groups (Tab.3). Mean platelet volume increased on day 11 of low and high dose groups (Tab.4). Platelet-large cell ratio increased of low dose group on day 11 (Tab.5). White blood cells counts were dropped greatly on day 7 of 3 dosage groups (Fig.9).

2.2.3 Clotting time, bone marrow nucleated cells count and bone marrow DNA content The clotting time of cyclophosphamide low and high dose groups detected by capillary tube method were longer than that of Normal group, and the difference between cyclophosphamide low dose group and Normal was significant (Tab. 6). The bone marrow nucleated cells and bone marrow DNA content (Tab. 7) of cyclophosphamide low and high dose

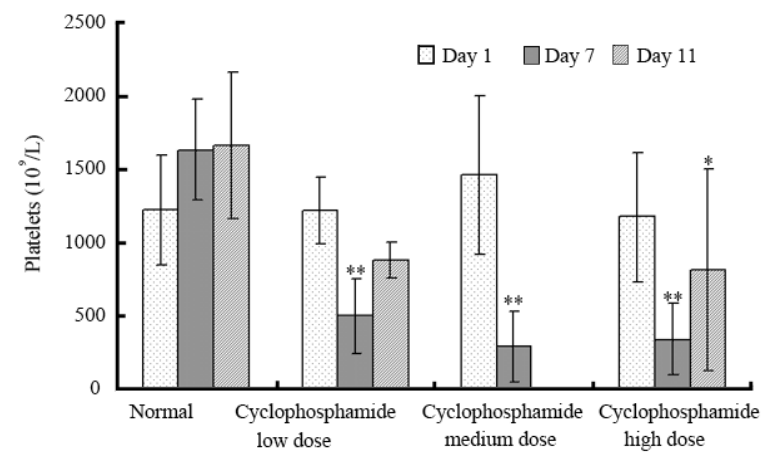

Fig. 8 Platelets of BALB/c mice influenced by cyclophosphamide on day 1 , day 7 and day 11

Data were expressed as $(\bar{X} \pm s)$. Compared to Normal on the same day: ${ }^{*} P<0.05,{ }^{* *} P<0.01$.

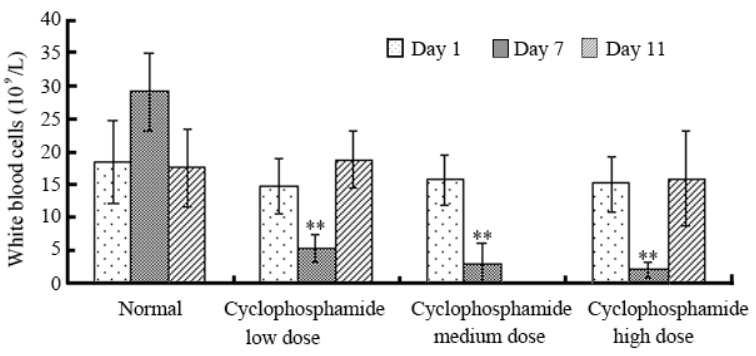

Fig. 9 White blood cells of BALB/c mice influenced by cyclophosphamide on day 1 , day 7 and day 11

Data were expressed as $(\bar{X} \pm s)$. Compared to Normal on the same day: $* * P<0.01$ 
Tab. 6 Effect of cyclophosphamide on clotting time of BALB/c mice ( $\bar{X} \pm s)$

\begin{tabular}{|c|c|c|c|c|}
\hline \multirow{2}{*}{ Group } & \multirow{2}{*}{ Dose $(\mathrm{mg} / \mathrm{kg})$} & \multirow{2}{*}{$\mathrm{N}$} & \multicolumn{2}{|c|}{ Clotting time (s) } \\
\hline & & & Capillary tube method & Slide method \\
\hline Normal & - & 11 & $179.36 \pm 74.29$ & $114.09 \pm 71.91$ \\
\hline Cyclophosphamide low dose & 100 & 2 & $374.50 \pm 12.02^{* *}$ & $220.50 \pm 135.06$ \\
\hline Cyclophosphamide high dose & 140 & 6 & $248.00 \pm 113.60$ & $143.33 \pm 121.15$ \\
\hline
\end{tabular}

Tab. 7 Effect of cyclophosphamide on bone marrow nucleated cells count and bone marrow DNA content detection of BALB/c mice $(\bar{X} \pm s)$

\begin{tabular}{lcccc}
\hline \multicolumn{1}{c}{ Group } & Dose $(\mathrm{mg} / \mathrm{kg})$ & $\mathrm{N}$ & $\begin{array}{c}\text { Bone marrow nucleated } \\
\text { cells count }\left(10^{7} / \text { femur) }\right.\end{array}$ & $\begin{array}{c}\text { Bone marrow DNA content } \\
\text { (Absorption value) }\end{array}$ \\
\hline Normal & - & 11 & $1.137 \pm 0.347$ & $0.90 \pm 0.46$ \\
Cyclophosphamide low dose & 100 & 2 & $0.913 \pm 0.633$ & $0.62 \pm 0.46$ \\
Cyclophosphamide high dose & 140 & 6 & $0.905 \pm 0.467$ & $0.66 \pm 0.30$ \\
\hline
\end{tabular}

groups were lesser than those of Normal group, but their differences were of no significance because their sample number varied too much and their standard deviation was too great.

\section{Discussion}

The suppressive effect of cyclophosphamide on haematogenesis is well known. The aim of the comparison experiment was to find out a feasible model of thrombopenia of mice induced by cyclophosphamide at two different administration routes. Mice in Model A tended to be more affected by cyclophosphamide, as its body weight decreased more and died sooner compared with those of Model B. The effect of thrombocytopenia was greater in mice of Model B, which was much more stable than that of Model A, as the platelets count significantly decreased on day 7 and day 11 and with no death within 13 days. The platelets of Normal increased slightly at the 7 th day, which may be correlated with the stimulation and compensation of blood lost. Through blood cell analyses and weight changes, it was clear that self-healing was induced towards the toxicity created by cyclophosphamide. This accorded with the clinical marrow inhibition adverse response of cyclophosphamide, where white blood cells decreased and the lowest amount of platelet occurred after administration of 1-2 weeks and self healing occurs 2-3 weeks later. We tested the clotting time and counted bone marrow nucleated cells at the end of this experiment. There was no significant difference of those two indices between Normal and model groups, which may be due to the haematogenesis recovering to almost normal level at that time interval. But these phenomena did not mean the toxic effects of cyclophosphamide were eliminated, but actually increased the number of deaths day by day.

In Model B, platelet distribution width, mean platelet volume and platelet-large cell ratio increased and white blood cell decreased sharply. Platelet distribution width is an indication of variation in platelet size which can be a sign of active platelet release. As for mean platelet volume, its elevated level is an indication of increased megakaryocytic shedding of platelets and abnormally high values correlate primarily with thrombocytopenia. Platelet large cell ratio increases in thrombocytopenia, and is inversely related to platelet count and directly related to platelet distribution width and mean platelet volume (Babu \& Basu, 2004). Cyclophosphamide, a chemotherapy drug, also well known as a potent immunosuppressive drug in humans and experimental animals, can reduce white blood cell. The white blood cells count data was coordinated with that of one article previously reported, which was first dropped sharply and then raised (Masahiro et al, 1999).

It was clear that Model A could reduce platelet to some extent and last for a longer time, however, mice of the group died rapidly and the platelets count was not stable. This differed from the descriptions of Zhang et al. (2003). We used mice of both sexes, at the body weight range of 17-21g, whereas Zhang et al(2003) only used males at the age of 6-8 weeks. Whether the aspects of sex, age and/or body weight variation can lead to those differences needs further exploration.

The administration route of Model B, subcutaneous injection, was used to carry out the following cyclophosphamide dosage modification experiment to seek a suitable dosage which is most effective for inducing thrombopenia with less toxic effect.

From the results of blood cell analyses, platelets and 
white blood cells of the three dosage groups dropped sharply in comparison with the Normal group. Cyclophosphamide high dose affected the mice much more than low and medium dosages. Day 7 was suitable for inducing thrombocytopenia. Furthermore, the low dose $(100 \mathrm{mg} / \mathrm{kg})$ could be a suitable dosage as the platelets count did not decrease as much as the other two dosages, allowing the treatment drug to ameliorate it. Platelets' function is to take part in the clotting process. Thrombocytopenia happens when platelets are lost from the circulation faster than they can be replaced from the bone marrow where they are made. Our experimental results showed mice in the model groups having the trend of prolonged clotting time and decreased bone marrow nucleated cells and bone marrow DNA contents, however, those parameters had no statistical significant difference when comparing with Normal group's.

\section{References:}

Babu E, Basu D. 2004. Platelet large cell ratio in the differential diagnosis of abnormal platelet counts [J].Indian $J$ Pathol Microbiol, 47(2): 202-205.

Chen L, Waxman DJ, Chen D, Kufe DW. 1996. Sensitization of human breast cancer cells to cyclophosphamide and ifosfamide by transfer of a liver cytochrome P450 gene [J].Cancer Res, 56(6): 1331-1340.

Cox PJ. 1979. Cyclophosphamide cystitis-identification of acrolein as the causative agent [J]. Biochem Pharmacol, 28(13): 2045- 2049.

de Jonge ME, Huitema ADR, Rodenhuis S, Beijnen JH. 2005. Clinical pharmacokinetics of cyclophosphamide [J]. Clin Pharmacokinet, 44(11): 1135-1164.

He WS, Liu AH, Shi LM. 1984. In vivo induction of chromosomal aberration in liver, bone-marrow and spermatogonial cells in mice by benzene and cyclophosphamide [J]. Zool Res, 5(2): 175-179 (in Chinese).

He XL, Yin HL, Liu XX. 2003. Copying of throbbocytopenic model and effect of interleukin- 6 on increase of platelet in experiment mice [J]. Sichuan J Zool, 22(2): 121-122 (in Chinese) .
Increasing the sample size may produce a significant result.

In conclusion, $\mathrm{BALB} / \mathrm{c}$ mice challenged by subcutaneous injection of $100 \mathrm{mg} / \mathrm{kg}$ cyclophosphamide once a day for 3 days consecutively could be a feasible mouse model of thrombocytopenia induced by cyclophosphamide. The 7th day is the most suitable test point. The platelets count of mice in this thrombocytopenia model was definitely reduced and stable. This model is easy to mimic, and is suitable for pharmacodynamic test of the drugs that are designed to increase platelets counts.

Acknowledgements: Thank you to Scott Groom for his efforts in correcting and improving the English writing of this paper.

Legha SS, Buzdar AU, Smith TL, Hortobagyi GN, Swenerton KD, Blumenschein GR, Gehan EA, Bodey GP, Freireich EJ. 1979. Complete remissions in metastatic breast cancer treated with combination drug therapy [J]. Ann Intern Med, 91(6): 847-852.

Lü QJ. 2007. Methodology of New Drug Research in Pharmacology [M]. Beijing: Chemical Industry Press, 326 (in Chinese)

Masahiro K, Takuya K, Yoshio K, Hiroaki T, Kikuo N, Takafumi Y. 1999. Accelerated recovery from cyclophosphamide-induced leukopenia in mice administered a Japanese ethical herbal drug, Hochu-ekki-to [J]. Immunopharmacology, 44(3): 223-231.

Shou QY, Ying HZ, Zhou WM, Chen ML, Lin L. 2008. Comparison of mouse models of cyclophosphamide-induced leucopenia at two administration methods [J]. Lab Anim Comp Med, 28(4): 266-268 (in Chinese) . .

Zhang Q, Peng HJ, Yu XB, Xu PL. 2003. Establishment of a mouse model of cyclophosphamide-induced thrombocytopenia and determination of platelet function of this model [J]. J Fist Mil Med Univ, 23(12): 1277-1282 (in Chinese) . 